\title{
The Theory and Practice Study of Classroom Quality Academic Evaluation of Chinese Classroom
}

\author{
Fangfang Xiong ${ }^{1, \text { a }}$ \\ ${ }^{1}$ Nanchang Institute of Science \& Technology, Nanchang, Jiangxi, 330000 \\ a email
}

Keywords: Language Class; Qualitative Academic Evaluation; Practice

\begin{abstract}
The improvement of a course needs to be implemented through the teaching evaluation, teaching evaluation can be said that the process of teaching and teaching traction rope. The progress of the new curriculum reform is inseparable from the role of teaching evaluation, and only the problem in the teaching evaluation can be found to further deal with more problems. Classroom quality evaluation is a stepping stone to improve the teaching evaluation, has been widely recognized in the field of social education. In the United States in the educational practice, qualitative evaluation of the impact of language teaching evaluation is minimal. This paper expounds the present situation and development trend of the qualitative teaching evaluation in terms of theory and practice. This paper makes a detailed description of the emergence and development of the qualitative evaluation in theory, and studies the connotation and significance of the qualitative teaching evaluation. In practice, this paper studies the status quo and problems of the current quality of language teaching evaluation, and analyzes the problems that arise, and then elaborates the suggestions of developing qualitative academic evaluation. This article can help the relevant research work.
\end{abstract}

\section{Introduction}

Language as a history has been a century of discipline, in the current language teaching practice can only still exist a lot of problems the most important reason comes from the teaching evaluation. Chinese teaching evaluation is the traction rope of Chinese teaching. If you want to deal with the problems in language education and promote the process of Chinese teaching reform, you need to start from the evaluation of Chinese teaching. Qualitative evaluation is a new concept of evaluation, from the qualitative research gave birth, from creation to development, but also a few decades time. The characteristics of Chinese disciplines make qualitative evaluation play an important role in the evaluation of Chinese teaching, but there are few researches on the evaluation of qualitative teaching of language subject [1]. In general, both the qualitative evaluation and the evaluation of the qualitative teaching evaluation of the liberal arts are still at the primary level. In the context of the current popularization of language education and qualitative evaluation, the problems hidden in it are becoming more and more obvious.

\section{The Concept Overview of Language Quality Teaching Evaluation}

The main purpose is to improve the level of students 'language literacy and realize the all-round development of students. The main purpose of this paper is to improve the students' language literacy level. The evaluation of language quality teaching refers to the comprehensive evaluation and analysis of the students' learning status, behavior and level in the language learning environment, which is based on humanistic epistemology in the teaching of Chinese teaching. Students 'language learning characteristics, so as to promote students' language literacy has been significantly improved. The qualitative teaching evaluation is part of the qualitative teaching evaluation, and it is also the development of the qualitative evaluation to the Chinese language. So the quality of language teaching evaluation has the characteristics of qualitative evaluation. Language disciplines and because of their own characteristics and qualitative evaluation can be a good combination. The effective set of the two can greatly fill the shortcomings of the quantitative 
evaluation, qualitative evaluation of the characteristics of the language quality of teaching evaluation needs to be reviewed from a number of aspects of the students, but also to students in the process of learning the language can find the problem And solve the problem, so that students regardless of language literacy or language learning have been improved.

\section{The Status Quo and its Problems in the Evaluation of Qualitative Teaching}

According to the basic principles of Chinese teaching evaluation, which is expressed in the Chinese Language Curriculum Standard, the ultimate goal of the evaluation is to promote the effective improvement of students 'language literacy. The evaluation needs to actively play the function of judgment, encouragement and development, and explain the students' the key to the evaluation. "Full-time compulsory education language curriculum standards" in the teaching evaluation made a detailed description of the evaluation to be combined with the evaluation of teachers, students themselves self-evaluation and evaluation between students and other points of view. Education departments and schools at all levels have also spent a lot of time to carry out education and training, the vast majority of teachers have also accepted the corresponding evaluation of the same quality evaluation of the form of learning [2]. But we can find from the relevant research, the current status of the implementation of Chinese language subject evaluation is more worrying. To a large extent, many students and parents know little about qualitative evaluation and teachers as the implementation of the teaching evaluation of the main body, although received the appropriate counseling training, but also for various reasons to qualitative evaluation aside and some Teachers have never been in the class to carry out quality evaluation activities. To promote the quality of language teaching evaluation is difficult to carry out in the language teaching, resulting in the advantages of qualitative evaluation gradually forgotten. The most ideal language teaching evaluation is the organic unity of qualitative evaluation and quantitative evaluation. It is also actively advocated by the curriculum standards. But from the reality, the share of qualitative evaluation in teaching evaluation is almost a few.

There are several differences in the implementation of language quality teaching evaluation in the process of implementation: First, the evaluation of the implementation of the language and quality of the evaluation of the quality of teaching students has different views. After a series of surveys, the author found that almost more than half of the parents, students, and even teachers who have received professional training, the quality of the evaluation are difficult to form a correct understanding, let alone hope that teachers can qualitative evaluation and the combination of Chinese teaching evaluation. Some teachers can distinguish between qualitative evaluation and student development evaluation and encouragement evaluation. Some teachers can not distinguish between qualitative evaluation and language disciplines, and lack the consciousness of organic combination of Chinese subject and qualitative evaluation. Second, the quality of language teaching evaluation is in the specific implementation of the process of confusion. The results of qualitative evaluation Compared with quantitative evaluation, the form of expression may not be intuitive. In the qualitative evaluation, it is necessary to show the characteristics of the subject of the language and how many problems arise. These problems also promote the confusion of the qualitative teaching evaluation in the concrete implementation process. According to the survey, many language teachers in the jurisdiction of their own class in the implementation of the portfolio evaluation, and later implemented for some time and after a variety of reasons canceled, the most important reason may be difficult in the specific operation. There are some teachers holding full of blood began to qualitative evaluation, because of its superficial cognition and difficult to implement, these practices are difficult to qualitative evaluation and language teaching evaluation of each other.

\section{Evaluation Difficult Reasons of Qualitative Teaching}

At present, the curriculum standards and teaching evaluation reform syllabus need to ask the educators to change the method of Chinese teaching evaluation in a certain sense, and improve the status of qualitative evaluation in the evaluation of Chinese teaching. However, these are only 
developed to the extent of advocacy, if not fundamentally change the examination of Chinese language in the evaluation of the subject, and then vigorously promote the qualitative evaluation are also doing unnecessary work. In addition, the implementation of the qualitative evaluation process, if the lack of corresponding regulatory mechanisms will make development fall short.

The qualitative evaluation is not as practical and intuitive as the quantitative evaluation, so the qualitative evaluation is also faced with great difficulties in the combination with the Chinese subject. Language quality teaching evaluation is now a lack of compliance model, the education sector at all levels to take to develop the implementation of norms, if only rely on the enthusiasm of teachers to explore, the results may not be good to the direction of development [3].

In the social context of enrollment rate, very few schools and teachers are willing to implement qualitative teaching evaluation at the risk of sacrificing the rate of enrollment. Whether the language teachers, students or parents believe that the test and the college entrance examination pressure is to support the quality of teaching evaluation carried out an important reason. In view of this, if you do not change the past in the examination and college entrance examination in the Chinese language evaluation methods, the implementation of language quality teaching evaluation is difficult to be substantial changes.

\section{The Language Classroom Quality Academic Evaluation of the Proposed Recommendations}

Among the many reasons for the development of qualitative evaluation, the evaluation of the concept of the old and new to its smooth implementation has a pivotal role. In view of this, we need to use modern advanced evaluation concept as the leading force, accelerate the reform process of Chinese language education. It is necessary to abandon the old concept which is not conducive to the development of students, and the new evaluation concept can be effectively set up.

Academic evaluation Humanism refers to the students in the academic evaluation, the evaluation of the main students to give enough respect and attention to the students as the core, change the traditional teacher-led thinking. At present, there is still a lot of practice in our academic evaluation, which lacks humanistic care. More emphasis is on the teaching of students' knowledge. The students' feelings are not paid much attention, which leads to poor students' interest. In view of this teacher to start from the humanistic care, students in the study of students always pay attention to the emotional thinking, to find students' progress and praise, and students to establish equal relations with students as friends.

Nowadays, the rapid development of society can not be separated from the injection of diversified talents. The school needs to diversify students' academic evaluation as a base for cultivating talents. Students' learning activities are closely related to life, and the purpose of student evaluation is to promote students to develop in an all-round way, to abandon only focus on the results of the students, learning attitude, learning habits and learning motivation and other factors should be real-time attention. Ignoring any point of content, are most likely to affect the future development of students. Therefore, we should create a holistic academic evaluation concept, a comprehensive and comprehensive assessment of the development of various aspects of the students, pay attention to the development of intellectuals at the same time, concerned about the development of other aspects of the students. Concerned about the results of students learn to stimulate students 'interest while learning, to develop students' learning attitude and habits. Teachers can also use some teaching methods to deal with the problems that exist, only from the focus on the overall development, create a holistic academic evaluation concept, in order to convert the knowledge of books to help student better life tools.

\section{Conclusion}

In summary, there are some problems in the language evaluation of the language class, such as teachers, students and parents to understand the quality of the evaluation, language quality teaching evaluation in the implementation process of cognitive confusion and other issues. The reasons for the development of the qualitative assessment are also related to the fact that the education 
departments at all levels remain in the stage of advocacy and the characteristics of language quality assessment. After a lot of research we can find that the quality of language teaching evaluation is to improve students' language literacy as the main goal, to promote the comprehensive development of students as the fundamental purpose. Qualitative evaluation and language disciplines can be effectively combined, and the implementation of qualitative evaluation in the language disciplines has a clear advantage. Educators can advance the further development of qualitative evaluation from the concept of student academic evaluation, the popularization of academic evaluation of humanistic care and the creation of holistic academic evaluation. We have reason to believe that in the language disciplines in the implementation of language quality teaching evaluation can fundamentally promote the development of student capacity.

\section{References}

[1] Wang Ping, Fu Zelu. Teacher's academic evaluation and practice of the relationship between the study based on the application of photo projection method [J]. Course teaching research, 2013, 10: 5-10.

[2] Zhou Liqun. Dynamic evaluation: a new perspective of Chinese curriculum evaluation [J]. Journal of South China Normal University (Social Science Edition), 2006, 03: 103-110

[3] Li Qingli, Liu Yuexia. Secondary school students qualitative academic evaluation research [J]. Industry and Technology Forum, 2016, 07: 155-156.

[4] Zhao Ningning, Wang Lu, Liu Qinqin, Shi Xian, Zhu Shenyue, Wang Xiuna. Discussion on the Elements of Environmental Support for Floating Children- Multilayer Linear Analysis of Chinese Children's Academic Achievement and Its Environmental Factors [J]. Journal of Education, 2016, 03: 54-67. 